\title{
Educando con medios alternativos
}

\section{Educating with Alternative Media}

\author{
José Alberto Rubí Barquero ${ }^{1}$ \\ Escuela de Filosofía \\ Universidad Nacional de Costa Rica \\ Heredia, Costa Rica \\ joserubi54@yahoo.com
}

Recibido 10 de noviembre de $2010 \bullet$ Aceptado 09 de marzo de 2011

Lo fascinante del cine es colocar al espectador en posiciones morales en las que nunca estuvo.

Alex De La Iglesia

Resumen. Este artículo nace de mi interés por explorar caminos que hagan de la experiencia educativa que se vive diariamente en las aulas, una actividad más interesante y placentera; es por ello que exalto las posibilidades que como medio pedagógico tienen el cine y, en general, los medios audiovisuales, junto con la conveniencia de que los educadores recurran a ellos como alternativas enriquecedora de su desempeño profesional.

Palabras claves. Educación, mediación pedagógica, cine, medios alternativos.

Abstract. This paper emerges from my interest in exploring ways to transform the daily classroom educational activity into a more pleasant and interesting experience. In this regard, I call attention to the possibilities of cinematography and other audiovisual media as pedagogical means, and the advisability for educators to use them as enhancing alternatives to their professional performance.

Keywords. Education, pedagogical mediation, cinematography, alternative media.

\section{Introducción}

El año pasado, cuando hacía poco que había leído el libro Mediación pedagógica, (Gutiérrez y Prieto, 2004), lectura que me sirvió de base para escribir el ensayo: Una mediación ética, psicológica y ecoligizante, uno de mis colegas me invitó a participar en

Doctor en Educación y Licenciado en Filosofía. Es profesor en la Escuela de Filosofía de la Universidad Nacional de Costa Rica. 
un cine fórum del documental La verdad incómoda de Al Gore (Gore, 2006). Junto con la invitación, mi colega me indicó que podía asistir a una exhibición del documental, con cupo restringido, que se iba a llevar a cabo en esa semana para que así tuviera elementos de juicio el día de mi participación en el cine fórum.

Acepté participar en el cine fórum, pero le dije que no necesitaba ver el documental, que para lo que pensaba plantear me bastaba con lo que había leído en la prensa acerca del trabajo de Gore, donde se decía, entre otras cosas, que estaba dedicado a mostrar que efectivamente nuestro planeta Tierra, como producto en buena parte de la actividad humana, estaba sumido en un proceso de calentamiento global y las consecuencias que para la vida en general y la humana en particular trae consigo dicho fenómeno.

Para mí, en ese momento, el tema del calentamiento global, también conocido como efecto invernadero, no era un tema nuevo; por el contrario, era un tema del que me venía ocupando en mis cursos de temática ambiental desde finales de los años ochenta. Por lo tanto, sabía que había toda una polémica al respecto y que en esa polémica una de las partes, la más poderosa económica y políticamente en el mundo, insistía, con diferentes argumentos, en negar la realidad del calentamiento global o, en el mejor de los casos, en minimizar su importancia. Así que el enterarme de la existencia de un documental que le daría la vuelta al mundo mostrando que el cambio climático, entendido como calentamiento global, era un hecho innegable junto con las consecuencias que se le venían atribuyendo, como el deshielo de los polos, era algo que no me podía dejar indiferente.

Por eso acepté la ya mencionada invitación de mi colega. Y como estaba bajo el influjo de mis lecturas relacionadas con la mediación pedagógica y de lo que había escrito desde mi tema que tiene que ver con la nueva ética de raigambre ecológica, decidí participar en el foro para hablar, no del contenido del documental, eso se lo dejaría a mis compañeros de mesa, sino para referirme a los alcances que como herramienta pedagógica puede tener un documental como este de Gore, que para ese momento ya todos los presentes habríamos visto. En otras palabras, quería poner en discusión si el aprendizaje y la toma de conciencia que se busca al abordar los llamados problemas ambientales, se facilitan utilizando medios audiovisuales y, de ser afirmativa la respuesta, considerar las condiciones necesarias para que eso sea posible. He aquí, por escrito, lo que dije en esa ocasión:

\section{A propósito de "Una verdad incómoda"}

Einstein citado en Radmanesh (2006, p. 97) dijo una vez: "No se puede resolver un problema desde el mismo estado de conciencia que lo provocó". Este feliz hallazgo del famoso físico se aplica, con especial pertinencia, a los problemas ambientales, incluido, claro está, el problema del calentamiento global.

Muchos de los problemas que hoy nos agobian, que nos tienen al borde del colapso como civilización, tienen que ver con el predominio que una visión del mundo y de la vida, fragmentaria y mecanicista, llegó a tener durante el período moderno. Una visión, un paradigma, que pese a su agotamiento, a su evidente caducidad, sigue permeando las conciencias actuales.

Esto explica, por ejemplo, que para los problemas creados por una visión centrada en el crecimiento se nos ofrezca, como solución, más crecimiento, algo así como pretender aplacar un incendio con la ayuda de algún líquido inflamable. Lo mismo podemos observar con los problemas creados por un sistema escolar inoperante y al que se le sigue viendo, sin embargo, como parte de la solución. 
Surge, entonces, la siguiente pregunta: ¿Cómo hacemos para que el surgimiento de una nueva conciencia sea parte de un proceso que involucre cada vez a más personas, para que los cambios que trae consigo una nueva conciencia trasciendan la esfera individual, los pequeños grupos y lleguen a tener repercusión planetaria?

Esta pregunta me lleva a tomar en cuenta la educación, pues así como ha servido, hasta el día de hoy, para conformar una conciencia fragmentaria y de inspiración mecanicista, puede servir, de ahora en adelante, para promover el surgimiento de una nueva conciencia, esta vez de carácter integral, holística, alternativa.

Es en este contexto que quiero ubicar el documental Una verdad incómoda (Gore, 2006), a propósito del tema del calentamiento global. Para ello, voy a traer aquí la preocupación que en días pasados, cuando se celebraba el día de la libertad de expresión en nuestro país, confesaba un ex presidente, en el sentido de lo peligroso que era, para la buena salud de la democracia costarricense, el hecho de que la propiedad de los medios informativos se estuviera concentrando cada vez en menos manos.

La misma preocupación deja ver Gore en una entrevista para El País Internacional (Martí, 2006) cuando dice:

(...) Hace 50 años llegó la televisión como la fuerza dominante. Esto supuso una regresión a los monasterios medievales, porque la fuente de los mensajes quedó en manos de muy pocos. Ahora el individuo ya no puede intervenir en la conversación por encima de los medios de comunicación dominantes. (párr. 19).

\section{¿Qué arma tiene ahora el individuo para recuperar la conversación?}

Internet está empezando a desafiar la televisión, aunque no tiene la capacidad de distribuir instantáneamente y en todas las direcciones las imágenes televisadas. Es esta cualidad hipnótica de la televisión, la que le proporciona ese atractivo masivo. Internet representa para mí la esperanza de recrear la conversación de la democracia (...). (párr.. 20-21)

\section{[Periodista] ¿Está enfermo el modelo democrático?}

Junto a la crisis del clima tenemos una crisis de la democracia, y para resolver la crisis del clima debemos abordar también la crisis de la democracia. Pero disponemos de las herramientas para hacerlo, porque con Internet, y con el video digital, y con la posibilidad de hacer películas como Una Verdad Incómoda, podemos poner ante los ojos de la gente verdades que sirvan de base para pasar a la acción. (párr. 22-23)

En esta misma línea, en un libro que lleva el sugestivo título de Placer y ternura en la Educación. Hacia una sociedad aprendiente, Assmann (2002) plantea:

Está surgiendo una hipótesis desafiante: la humanidad ha entrado en una fase en la que ningún poder económico o político es capaz de controlar la explosión de los espacios del conocimiento. Internet es un ejemplo para entender lo que se quiere decir con esta hipótesis. 
Por eso, la dinamización de los espacios del conocimiento se ha convertido en la tarea emancipatoria políticamente más significativa. Dicho de otro modo, parece que se ha abierto una brecha entre acumulación de capital y explosión y difusión de los conocimientos. Si eso fuese verdad, corresponde a la educación penetrar a fondo en esa brecha. (p. 27)

Se trata, agrego yo, de educarnos para hacer un uso alternativo de los medios que pueden ser alternativos, porque estas prodigiosas herramientas tecnológicas igual pueden servir en un proceso emancipatorio, en el alumbramiento de una nueva conciencia, como en un proceso de signo contrario, donde lo que se busca es adormecer la conciencia de la gente en aras de una manipulación más efectiva.

Todavía está fresco en mi memoria, a propósito de estas herramientas tecnológicas que pueden ser alternativas, el torrente de mensajes de texto que circularon por el teléfono celular, cargados de las más lamentable xenofobia, aludiendo al indigente nicaragüense Natividad Canda que murió víctima de las mordeduras de perros rottweiler en la Lima de Cartago. Y si uno se pusiera a inventariar toda la basura que ofrece la red de Internet y todo el bombardeo publicitario que en gran medida es la televisión, el resultado no sería como para hacerse muchas ilusiones.

Salvo, claro está, que oportunidades como esta, con medios pedagógicos como Una verdad incómoda y con el espacio necesario para su debate, en un medio cultural como el nuestro, dejen de ser la excepción y pasen a convertirse en la regla.

\section{Lo alternativo en educación}

Nunca he permitido que la escuela entorpezca mi educación

Mark Twain

Gutiérrez y Prieto (2004), reflexionando acerca de la educación abierta, se preguntan por lo que hace que un sistema de educación abierta sea alternativo. Y como en un sistema de educación abierta los medios tecnológicos, en general, y los audiovisuales, en particular, ocupan un lugar central, su respuesta a esa pregunta tiene mucho que ver con lo que intenté plantear en el foro acerca de Una verdad incómoda.

\section{Una verdad incómoda}

De acuerdo con Gutiérrez y Prieto (2004), para que la educación abierta sea alternativa debe presentar las siguientes características:

a. Ser participativa a pesar de la distancia

b. Partir de la realidad y fundamentarse en la práctica social del aprendiente

c. Promover en los agentes del proceso actitudes críticas y creativas

d. Abrir caminos a la expresión y a la comunicación 
e. Promover procesos y obtener resultados

f. Fundamentarse en la producción de conocimientos

g. Ser lúdica, placentera y bella

h. Desarrollar una actitud investigativa. (p. 25)

Estas características, igualmente, se le pueden pedir a la educación presencial. Educación, esta última, que también gana mucho cuando recurre a un uso alternativo de los medios tecnológicos como aliados en su mediación pedagógica.

Ningún medio tecnológico, ya sea internet, la televisión o el cine, es per se educativo, emancipatorio. Veamos, por ejemplo, lo que sucede con el cine cuando se rige por las solas leyes del mercado:

"Diez fueron los filmes que atraparon a los ticos en los meses pasados". Este dato acompaña al título Los reyes de la taquilla de la portada del suplemento Viva de La Nación (Fernández, 2007, p. 5). En la página 5 de dicho suplemento viene el siguiente cuadro con los detalles de la información:

En Costa Rica Spider-Man 3 dominó la taquilla

\begin{tabular}{|l|c|c|c|}
\hline Película & Asistentes & Semanas & Recaudación millones de colones \\
\hline Spider-Man 3 & 259945 & 9 & 473 \\
\hline Shrek 3 & 239808 & 6 & 437 \\
\hline Transformer & 234983 & 10 & 428 \\
\hline Harry Potter y la orden del Fénix & 224014 & 9 & 408 \\
\hline Piratas del Caribe & 191660 & 7 & 349 \\
\hline En el fin del mundo Ratatuoille & 178017 & 10 & 324 \\
\hline Los Simpson & 166705 & 11 & 303 \\
\hline Los 4 fantásticos y Silver Surfer & 95388 & 5 & 173 \\
\hline Ocean's 13 & 33354 & 7 & 60 \\
\hline Duro de matar 4.0 & 24780 & 6 & 45 \\
\hline
\end{tabular}

Este cuadro no puede ser más elocuente. Es por esto que el día que se llevó a cabo el foro del que he venido hablando, yo no podía salir del asombro al ver una de las salas de cine del mall Las Flores, en Heredia, repleta de estudiantes de la Universidad Nacional, absortos todos con lo que iba diciendo y presentando Al Gore desde su documental.

Ese día, la persona que organizó la actividad logró que desde la sala de cine, normalmente dedicada al cine como actividad comercial, la película Una verdad incómoda, el público asistente y el foro tuvieran las características de lo alternativo.

Y no es que uno, en este caso, tenga que estar de acuerdo con todo lo que plantea Gore en su documental. A mí personalmente sus propuestas de solución al problema del calentamiento global no me parecieron las más acertadas, en algún momento las sentí como más de lo mismo, como cuando le aconseja a los fabricantes de autos de su país que imiten a los fabricantes japoneses, porque ellos sí han sabido fabricar autos económicos y menos contaminantes. Pero para eso era el foro, para discutir la película. Porque esta y todas las películas hay que discutirlas, aunque sea a solas con uno mismo. Si no, uno se queda como poseído por los demonios que el cine nos sabe introducir con su particular forma de decirnos las cosas. 


\section{Conclusión}

Siendo todavía estudiante en la Universidad de Costa Rica, estudiante de la carrera de Filosofía, recuerdo que uno de los profesores nos aconsejaba que lleváramos los cursos de Educación para que al final el título fuera en la Enseñanza de la Filosofía y que yo no le hice caso porque, en ese momento, la idea de ser profesor no me atraía. Pero también recuerdo que cuando otro de mis profesores, tiempo después, me preguntó que si yo aceptaba dar unas clases de Filosofía en un colegio donde el director era un amigo suyo, le dije que sí, que aceptaba el reto. Así fue como me inicié en la docencia.

Quizás por mis lecturas de Platón, porque el hecho de que sus escritos filosóficos tuvieran forma de diálogo me resultaba muy estimulante, yo quería que mis clases tuvieran ese carácter de diálogo donde todos hacen su aporte y no solo el profesor. Este propósito que todavía me acompaña, me hacía salir de mis clases con el sinsabor de que no estaba haciendo las cosas bien, dado que el nivel de participación que lograba no era el que yo quería. Evidentemente necesitaba ayuda y esa ayuda me vino, sin esperarlo, de los audiovisuales. Solo cuando vi el diálogo que se armó el día en que para introducir uno de los temas se me ocurrió llevar una película, me di cuenta de la importancia pedagógica de este tipo de recursos.

Hoy, muchos años después de ese descubrimiento, sigo reforzando mis cursos con unas cuantas películas de esas que realmente conmueven al espectador y lo obligan a una revisión integral de su visión del mundo y de la vida. Gracias al cine y a sus múltiples capacidades, un día pude decirle a uno de mis estudiantes que sí, que mi curso de Ética ambiental incluía giras, como él lo esperaba, pero que eran giras virtuales y que una de ellas era una visita a la selva amazónica, cuando viéramos en la clase la película de John Boorman's, The emerald forest.

\section{Bibliografía}

Assmann, H. (2002). Placer y ternura en la educación. Hacia una sociedad aprendiente. Madrid: Narcea. Recuperado de http://es.scribd.com/doc/52694668/Hugo-Assman-Placer-y-ternura

Fernánez, V. (Domingo 14 de octubre de 2007). Los reyes de la taquilla. La Nación (Suplemento Viva), p. 5.

Gore, A. (Productor), Guggenheim, D (Director). (2006). Una verdad incómoda [Documental]. Estados Unidos: Paramount Pictures.

Gutiérrez, F. y Prieto, D. (2004). La mediación pedagógica. Apuntes para una educación a distancia alternativa (10 ${ }^{\mathrm{a}}$ ed.). Falta la ciudad: La Copia Fiel.

Martí, J. M. (25 de junio de 2006). El profeta del cambio climático. El país. Recuperado de http:// elpais.com/diario/2006/06/25/eps/1151216807_850215.html

Radmanesh, M. (2006). Cracking The Code of Our Physical Universe: The Key to a World of Enlightenment and Enrichment. Estados Unidos de América: AuthorHouse. 